\title{
TESTIMONIO Y COMPROMISO: \\ UNA VISIÓN DIFERENCIAL EN LA LITERATURA ESPAÑOLA CONTEMPORÁNEA PRESENTACIÓN DE LA EDITORA DEL MONOGRÁFICO
}

FRANCISCA VILCHES-DE FRUTOS

Consejo Superior de Investigaciones Científicas. CCHS-ILLA

francisca.vilches@cchs.csic.es

RESUMEN: Testimonio y compromiso van unidos en el discurso literario de las escritoras tratadas en este volumen: Lucía Sánchez Saornil (1895-1970), Federica Montseny (1905-1994), Dolores Medio (1911-1996), María Dolores Boixadós (1917-2008), Marta Sanz (1967), Angélica Liddell (1968), Llucía Ramis (1977), Elvira Navarro (1978) y Lola Blasco (1983). En el caso de los cuatro primeras, su juventud y madurez transcurrieron durante los años que precedieron a la proclamación de la Segunda República (1931), el estallido de la Guerra Civil (1936) y la dictadura militar impuesta en 1939, un período de cambios políticos y sociales importantes que implicaron, entre otras consecuencias, la necesidad de exiliarse al acabar la contienda o sobrevivir en ese exilio interior al que se vieron abocadas durante el franquismo las personas afines a los valores republicanos. En el caso de las autoras más jóvenes, sus vivencias de niñez, juventud y madurez se desarrollan ya en un país que eligió la democracia como régimen político tras la aprobación de la Constitución de 1978 Pero, sin olvidar los exilios de sus predecesoras, reaccionan ante otros éxodos provocados por las guerras y regímenes dictatoriales acontecidos en otros lugares del planeta, la crisis ocasionada por un sistema económico en vías de agotamiento y los problemas y limitaciones derivados de la diversidad funcional y de género. Poemas, una autobiografía, novelas, ensayos periodísticos, textos teatrales y performances son los cauces genéricos elegidos para transmitir sus experiencias de mujeres que han transitado la esfera pública.

PALABRAS CLAVE: Escritoras hispánicas contemporáneas, literatura, testimonio y compromiso. 


\section{TESTIMONY AND COMMITMENT: A Differential Perspective in Contemporary Spanish Literature}

ABSTRACT: Testimony and commitment come together in the literary discourse of the women writers studied in this issue: Lucía Sánchez Saornil, Federica Montseny, Dolores Medio, María Dolores Boixadós, Marta Sanz, Angélica Liddell, Llucía Rais, Elvira Navarro, and Lola Blasco. The first four spent their youth and maturity in a period of strong political and social changes (1931-1939) that brought, among other consequences, their exile after the Spanish Civil War and their hard survival under an inner exile that was almost compulsory for people of Republican values under Francoism. In contrast, the younger women writers' life experiences occurred in a Spain that chose a democratic political regime in 1978. Without forgetting the exile suffered by their predecessors, they reacted against other exodus provoked by dictatorial regimes and wars taking place all over the world, the crisis caused by an exhausted economic system, and the problems and limitations brought on by the lack of gender diversity. The women authors' poems, autobiographies, novels, journalistic essays, plays, and performances reveal not only their personal experiences, as we can observe in the analyses presented in this issue by outstanding specialists, but also the defense of ethical politics based on justice, liberty, and respect for diversity; a vision that undoubtedly offers a new perspective of women's agency in the public sphere.

KEYWORDS: Contemporary hispanic women writers; literature, testimony and commitment.

$\mathrm{T}_{\mathrm{e}}^{\mathrm{e}}$ estimonio y compromiso van unidos en el discurso literario de las escritoras tratadas en este volumen: Lucía Sánchez Saornil (18951970), Federica Montseny (1905-1994), Dolores Medio (1911-1996), María Dolores Boixadós (1917-2008), Marta Sanz (1967), Angélica Liddell (1968), Llucía Ramis (1977), Elvira Navarro (1978) y Lola Blasco (1983). En el caso de los cuatro primeras, su juventud y madurez transcurrieron durante los años que precedieron a la proclamación de la Segunda
República (1931), el estallido de la Guerra Civil (1936) y la dictadura militar impuesta en 1939, un período de cambios políticos y sociales importantes que implicaron, entre otras consecuencias, la necesidad de exiliarse al acabar la contienda o sobrevivir en ese exilio interior al que se vieron abocadas durante el franquismo las personas afines a los valores republicanos. En el caso de las autoras más jóvenes, sus vivencias de niñez, juventud y madurez se desarrollan ya en un país que eligió la democracia como régimen político tras la aprobación de la Constitución de 1978. Pero, sin olvidar los exilios de sus predecesoras, reaccionan ante otros éxodos provocados por las guerras y regímenes dictatoriales acontecidos en otros lugares del planeta, la crisis ocasionada por un sistema económico en vías de agotamiento y los problemas y limitaciones derivados de la diversidad funcional y de género. Poemas, una autobiografía, novelas, ensayos periodísticos, textos teatrales y performances son los cauces genéricos elegidos para transmitir sus experiencias de mujeres que han transitado la esfera pública en distintos períodos de la historia española contemporánea y defender una ética política basada en la justicia, la libertad y el respeto por la diversidad (Hartwig, 2017). El análisis de la manera en la que estas autoras han reflejado los principales hechos políticos y sociales, así como su imbricación con el cambio es fundamental para conocer la evolución del proceso de construcción de la identidad colectiva española durante el siglo XX y las dos primeras décadas del XXI. Como señaló Manuel Tunón de Lara en su Metodología de la historia social de España, la "historia de la literatura nos aporta, a veces, el testimonio irreemplazable y, casi siempre, una fuente de conocimiento para la vida cotidiana y las mentalidades" (1974: 128), una observación con la que coincidió Garasa, quien dio un paso más al escribir: "No debe olvidarse, por otra parte, que la relación literaturasociedad es mutua y que si lo social influye sobre la producción literaria, no es menos cierto que la literatura influye sobre la sociedad" (1973: 13).

Los artículos incluidos en este volumen sobre los poemas de Lucía Sánchez Saornil y la autobiografía de Federica Montseny permiten vislumbrar las profundas transformaciones del tejido social durante los años que precedieron a la Guerra Civil y las consecuencias de su desenlace para sus protagonistas femeninas. No puede entenderse la producción 
literaria y escénica del período sin profundizar en el compromiso de un sector amplio de la intelectualidad española con los valores políticos y culturales de la Segunda República, cuya idoneidad y legalidad fue sostenida incluso en años posteriores a la finalización del conflicto bélico, cuando todavía seguía presente la posibilidad del "retorno" tras la caída del fascismo en Europa. Así, el camino recorrido por Lucía Sánchez Saornil desde el ultraísmo hasta la literatura de denuncia es representativo del emprendido por otras tantas figuras de la cultura española ante el giro que fueron tomando los acontecimientos. Si al comienzo de la década de los veinte el reto estaba en la ruptura con los modelos expresivos precedentes, conforme van transcurriendo los años fue imponiéndose la consideración de que la verdadera vanguardia radicaba en el compromiso del intelectual con el cambio político y social como señaló José Díaz Fernández en $E l$ nuevo romanticismo. Polémica de arte, política y literatura (1930), un libro clave para comprender estas cuestiones. La crisis de valores y el escepticismo que parecían haberse adueñado de la sociedad española debían ser sustituidos por un nuevo romanticismo que generara la ilusión de alcanzar una sociedad más justa, igualitaria y pacífica. Pero conviene recordar también los importantes cambios en los modelos de identidad femenina que supusieron, sobre todo, la incorporación de las mujeres a puestos laborales reservados hasta el momento a los varones, su mayor acceso a la educación y la concesión del sufragio activo y pasivo, que posibilitó la presencia de mujeres en el Congreso como diputadas. Como Matilde de la Torre (1864-1946), María de la O Lejárraga (1874-1974), Isabel de Oyarzábal (1878-1974), Margarita Nelken (1894-1968) y Ma Teresa León (19031988), también Lucía Sánchez Saornil y Federica Montseny tuvieron una destacada militancia política en el espectro de la izquierda, desempeñaron cargos políticos y se movieron en los espacios del activismo asociacionista (Johnson y Zubiaurre, 2012), lo que sin duda influyó en la importancia concedida en sus creaciones a nuevos modelos de mujer alejados de los parámetros asociados a la condición femenina en una sociedad patriarcal como lo era la España de aquel entonces (Ena Bordonada, 2011). Es esta una vertiente del compromiso con el cambio social apenas tratada hasta estas dos últimas décadas en los ensayos destinados a analizar el fenómeno de la llamada "literatura social".
La creación poética de Lucía Sánchez Saornil puede servir de ejemplo de este doble compromiso, pues, como apunta Inmaculada PlazaAgudo, la poesía fue un género al que recurrieron con frecuencia las escritoras de la época por su accesibilidad y la posibilidad de cultivarlo en la intimidad. Ya desde sus primeros poemas se percibe ese interés por indagar en el proceso de construcción de la subjetividad femenina y de ofrecer modelos transgresores de feminidad en aspectos tan esenciales como la maternidad, las relaciones de pareja y la sexualidad. Destaca sin duda su incidencia en el amor como vínculo donde se evidencia la diferente socialización de hombres y mujeres: una meta y destino en sí mismo, lo que conlleva la incomunicación entre los sujetos. Sus poemas revelan una postura avanzada en torno a la consideración de la mujer, cuyo carácter "racional, pensante y autónomo" defiende y sobre el matrimonio, contra el que se manifiestan al coartar su libertad y realización, a la vez que apuntan, además, hacia otras posibles opciones sexuales, como el amor homosexual. No sorprende, pues, que dedique su Romancero de Mujeres Libres (1937) a subrayar el protagonismo femenino en el conflicto bélico de la Guerra Civil y presente una guía para las mujeres que suponga una mayor imbricación en el conflicto bélico. De ahí la presencia en la obra de mujeres del pueblo de gran valentía y fortaleza, en muchos casos ignorantes, como el que representa María Silva, nieta de uno de los Seisdedos que participó en el levantamiento de Casas Viejas.

Un objetivo semejante subyace en la autobiografía Mis primeros cuarenta años de Federica Montseny, donde se aprecia, además de la evolución de la vida política española, los términos en los que se produjo la progresiva incorporación de las mujeres al ejercicio de la política activa y su compromiso con los valores de igualdad y con la lucha antifascista, aspectos de gran interés a la hora de profundizar en los límites del género autobiográfico escrito por mujeres (Caballé, 2002). En efecto, Montseny, que fue la primera mujer ministra en España, con una dilatada vida literaria como autora de medio centenar de novelas escritas desde los años veinte, plasma el nuevo paradigma identitario de la mujer profesional en política y los recelos que suscitaba, como pone de manifiesto Pilar Nieva-de la Paz. Editada como libro en 1987, aunque sus primeros capítulos fueron publicados en Toulouse en 1949, la obra presenta la "historia interna" de 
la CNT desde su vinculación a ella y visibiliza la aportación ideológica y fáctica del anarquismo a la política española. Si bien es una crónica de gran interés para conocer los principales hechos, relaciones y debates entre los actantes de la política española del período de preguerra, Segunda República, Guerra Civil y exilio, su valor diferencial estriba en su deseo de mostrarse como protagonista y ejemplo de un nuevo modelo de mujer activa en política. De ahí la importancia prestada al modelo de educación alternativa recibida en el seno de su familia, los condicionamientos que para el ejercicio profesional tuvo la maternidad y la relevancia de promover nuevos roles de género, derivados de su trabajo como ministra y de las reformas legales y políticas llevadas a cabo por el Gobierno republicano. Como otras escritoras y políticas del período, presta una gran atención a reflejar las dificultades de la vida del exilio y la amargura experimentada tanto por las privaciones como por el desenlace de los acontecimientos.

Los términos del compromiso de las intelectuales españolas experimentan cambios a partir del final de la Segunda Guerra Mundial, tras la constatación del reconocimiento político del régimen franquista por las principales organizaciones políticas mundiales. Son textos de denuncia que evidencian las transformaciones del tejido sociopolítico del país durante ese período y de manera especial en relación con la consideración de la mujer (Montejo Gurruchaga, 2012). Abordan la crueldad e intransigencia de un régimen en su castigo a los vencidos y propugnan la necesidad de organizarse para una mejor supervivencia bajo una dictadura militar, mientras llega una posible reconciliación que posibilite el retorno colectivo de las personas que emprendieron el exilio. Dolores Medio y María Dolores Boixadós son dos escritoras representativas de este período, también en su condición de nexo entre la España "peregrina" y los que permanecieron bajo la dictadura franquista. Aunque Boixadós optó finalmente por el exilio en Venezuela y Estados Unidos, ambas vivieron y desarrollaron parte de su creación literaria en la España franquista de la inmediata posguerra y convirtieron el exilio en temática de sus novelas. Sin embargo, a pesar de que llegaron a presentarse a premios tan significativos como el Nadal (1944), en el caso de Boixadós; o el Concha Espina (1945), Nadal (1952) y Sésamo (1967), en el caso de Dolores Medio, dos de las obras analizadas en este volumen no llegaron a publicarse hasta décadas posteriores a su escritura:
Aguas muertas (1944) de María Dolores Boixadós, en 1970, y Celda común (1963), de Dolores Medio, en 1996. No debe sorprender, puesto que son creaciones que muestran las nefastas consecuencias que el desenlace de la guerra tuvo para los vencidos (Aguas muertas) o el surgimiento de los primeros movimientos de oposición al régimen franquista (Celda común) (Sanz Villanueva, 2010).

Como ocurriera con sus predecesoras, la demanda de reconocimiento de los derechos de las mujeres está presente en las creaciones de Dolores Medio y María Dolores Boixadós, aunque los términos del discurso sean distintos, habida cuenta del cambio en la consideración de las mujeres durante el franquismo, sujetas a las estrictas normas morales del nacional-catolicismo. Resultan significativas en este sentido las dos obras analizadas en este volumen por Juan Rodríguez de María Dolores Boixadós, Aguas muertas y Retorno. En la primera, una recreación de un universo casi exclusivamente femenino, se apunta el deseo de libertad e independencia de unas jóvenes sujetas a unos estrictos comportamientos que alentaban la sumisión al varón y a las convenciones sociales con el matrimonio como objetivo vital; unos comportamientos muy alejados de las aspiraciones de las mujeres identificadas con los afanes emancipatorios de la Segunda República. Son jóvenes que necesitan decidir por sí mismas sobre su propio destino. En Retorno ofrece también el protagonismo a una mujer, la narradora de la primera línea narrativa, una exiliada que recrea la nostalgia por la patria perdida, aboga por sentar las bases para una reconciliación que posibilite la vuelta de los exiliados y llama la atención sobre la necesidad de contribuir a la educación de las nuevas generaciones en aquellos ideales que quedaron relegados tras el desenlace de la guerra. Es esta una obra pionera en su denuncia del peligro de un holocausto nuclear, un tema con el que estaba familiarizada por su experiencia vital en Oak Ridge. En Celda común y Bibiana, Dolores Medio aborda la doble discriminación, de género y política, a la que se vieron sometidas las mujeres que participaron en las manifestaciones que acompañaron las primeras huelgas obreras y en las demandas de amnistía a los presos políticos. Como analiza Carmen Alfonso, no son mujeres activas en la Esfera pública, son madres y esposas que se manifiestan en contra de una situación política y social por las repercusiones en su familia, como muestra Bibiana Prats en

UNED. REI, 7 (2019), pp. 11-23

ISSN 2340-9029 
Bibiana, recreación de la manifestación de mayo de 1962 en apoyo de la huelga asturiana, o que sufren encarcelamiento, como en Celda común, un texto de carácter autobiográfico, donde se denuncia el modelo de identidad femenina vigente y algunas de las estrategias del régimen para combatir la disidencia en las cárceles.

Tras la aprobación de la Constitución (1978) y la llegada de la democracia a España se abren nuevas líneas de participación de las mujeres en el cambio político y social. Desde mediados de los ochenta se hace cada vez más patente la necesidad de reivindicar espacios de actuación y visibilidad en la esfera pública para unas mujeres cada vez más preparadas educativamente y deseosas de la independencia económica que brinda su incorporación al mercado laboral. En este contexto se explica el éxito de ventas de creaciones de escritoras que ofrecen su testimonio autobiográfico y recrean los cambios en los paradigmas identitarios acaecidos desde finales de los setenta hasta bien entrados los noventa, un fenómeno socioliterario que suscitó numerosas artículos en la prensa y la visibilidad de figuras nacidas entre la década de los veinte y los aledaños de los sesenta, como Carmen Martín Gaite (1925-2000), Josefina Aldecoa (1926-2011), Esther Tusquets (1936-2912), Marina Mayoral (1942), Montserrat Roig (1946-1991), Carme Riera (1948), Rosa Montero (1951) y Almudena Grandes (1960), entre otras. La ausencia de modelos ante los cambios en los paradigmas de género explica la atención prestada por las escritoras de estos grupos generacionales a los modelos de mujer presentados por sus antecesoras, comprometidas con los valores igualitarios republicanos y con la innovación estética, cuyos textos conocen reimpresiones o son publicados por primera vez (Nieva-de la Paz, 2018: 81 y ss). Sus creaciones contribuyeron sin duda a una creciente demanda de plena incorporación de la mujer en la sociedad civil y cultural del momento, que tuvo uno de sus hitos más relevantes años después, ya en pleno siglo XXI, en la promulgación de la "Ley Orgánica 3/2007, de 22 de marzo, para la igualdad efectiva de mujeres y hombres". Sin duda, la obligatoriedad de las autoridades públicas de velar por hacer efectivo el principio de igualdad de trato y de oportunidades entre mujeres y hombres en la creación, producción y distribución artística e intelectual, así como de promover la presencia

equilibrada de mujeres y hombres en los mismos, recogida en su Artículo 26, está facilitando el acceso de estas a la agencia cultural y el abordaje de enfoques temáticos que albergan una comprometida perspectiva de género (Vilches-de Frutos/Nieva-de la Paz, 2012).

Los textos de Marta Sanz (1967), Angélica Liddell (1968), Llucía Ramis (1977), Elvira Navarro (1978) y Lola Blasco (1983) analizados en este volumen pueden resultar representativos de la actitud de las escritoras españolas ante los cambios acaecidos en los últimos años del siglo XX y los primeros del siglo XXI. Los términos del compromiso cambian y se centran en la denuncia de las consecuencias que para el individuo tiene el sistema económico capitalista y sociedades cada vez más globalizadas debido al desarrollo de las nuevas tecnologías. Son obras donde se aborda la responsabilidad comunitaria en la era de Internet, los problemas derivados de los éxodos de ayer y hoy, el impacto en la salud mental de la crisis económica que sacudió recientemente el sistema capitalista, la necesidad de dar una respuesta social ante la desigualdad y la violencia de género en el entorno familiar, la integración de la diversidad funcional o la preocupación por la libertad de expresión en una sociedad cada vez más sustentada en protocolos de actuación y respeto a los tabús.

Como apunta Luisa García-Manso, la crítica hacia una sociedad cerrada a la diversidad y la defensa de acciones destinadas a erradicar los prejuicios asociados tradicionalmente a la misma cobran vigencia en el teatro aplicado y comunitario, donde determinadas comunidades y grupos adquieren protagonismo como creadores e intérpretes en un afán de democratizar la cultura y hacerla accesible para personas que suelen mantenerse al margen de los escenarios. Elige para ello el análisis de un proyecto de la Nave del Teatro Calderón, de Valladolid, donde las figuras de mediación o "facilitadoras" del proceso son asumidas por Lola Blasco, una de las pocas creadoras galardonadas con el Premio Nacional de Teatro, y Nina Reglero, directora de escena, vinculada a otro proyecto escénico, Navegantes. Los problemas derivados de los éxodos de ayer y hoy son el asunto prioritario de Fuegos (2017). Testimonios presenciales, titulares de prensa y fotografías, presencia de referentes míticos y el uso grotesco de códigos ligados a las redes sociales (García-Pascual, 2012) permiten

UNED. REI, 7 (2019), pp. 11-23

ISSN 2340-9029 
denunciar los procesos de aislamiento, racismo y xenofobia provocados por las inmigraciones derivadas de las guerras, reflexionar críticamente sobre ellos y trazar los paralelismos entre unos y otros. Alude, entre ellos, al exilio republicano de 1939, el Holocausto de la Segunda Guerra Mundial, la emigración de españoles por temas económicos, la inmigración en España y la guerra de Siria, en un claro testimonio de denuncia sobre cómo son las mujeres sus principales víctimas, ya que "si hay algo peor que ser mujer en este mundo.../ eso es ser mujer, extranjera y pobre".

El artículo de Cristina Sanz supone una contribución diferencial al conocimiento del impacto de la crisis económica en la narrativa española última, esa tendencia que ha llevado a hablar del nacimiento de un subgénero, la "novela de la crisis". Su acercamiento a obras como $L a$ trabajadora (2014), de Elvira Navarro; Clavícula (2017) de Marta Sanz, y Las posesiones (2018), de Llucia Ramis, muestra el interés de estas escritoras por asociar la inestabilidad psicológica con la precariedad vital y presentar las enfermedades mentales como "metáforas de la enfermedad social en que vivimos", adquiriendo así “estatus de alegoría histórica”. Su compromiso ofrece una visión alternativa de las imágenes de mujer (especialmente en el caso de Sanz), y profundiza en las implicaciones de estas narraciones a la hora de explicar la conexión entre la locura y los condicionamientos socioeconómicos (precariedad laboral, desempleo de larga duración, etc.). Son obras donde se muestra la desconfianza hacia la capacidad del Estado para proteger al individuo frente a la corrupción y el engaño y sugieren, como señala Cristina Sanz, un conjunto de preguntas cuyas respuestas han de buscarse desde una perspectiva de género. Como bien se recuerda, los trastornos mentales afectan al mismo porcentaje de hombres y mujeres, pero se constata una prevalencia de diagnósticos de trastornos de ánimo (depresión y ansiedad) en mujeres, frente a los trastornos de personalidad $\mathrm{y}$ adicciones en los hombres.

Esta atención por la defensa del individuo en una sociedad cada vez más globalizada subyace también en dos de las creaciones de Angélica Liddell analizadas por Julio Checa Puerta en este volumen, Una costilla sobre la mesa, publicada en 2019, y La letra escarlata, estrenada en Francia ese mismo año, dos obras complementarias al permitir la primera conocer mejor la génesis de la concepción escénica de la segunda. A través de sus incorporaciones de rituales y acciones performativas reconocidas por la dramaturga como "formas de penitencia", su objetivo es transmitir "todo aquello que la gente no quiere escuchar" y reafirmar "la verdad por oposición a la mentira”. Su preocupación por la libertad de expresión en una sociedad cada vez más sustentada en la generación de protocolos de actuación y de tabús le lleva a abordar los peligros potenciales en una de las reivindicaciones más destacadas de la sociedad en las últimas décadas, el respeto por la igualdad de derechos de mujeres y hombres. Ha sido ese tratamiento crítico a los excesos en la instrumentalización de esas reivindicaciones lo que llevó a la prensa a identificar su creación como una crítica al movimiento \#Metoo, que desde el año 2017 supone un antes y un después en cuanto a la denuncia y el rechazo público de las conductas abusivas por parte de los hombres, especialmente en lo concerniente a la industria audiovisual. Sin embargo, como apunta Checa Puerta, aunque desde posiciones aparentemente controvertidas, no es posible cuestionar en las creaciones de Angélica Liddell algo que pudiera denominarse "un triple compromiso": con ella misma, con el arte y con la sociedad en la que se desenvuelve.

Como se puede apreciar, el análisis de las obras de estas creadoras, nacidas en distintos períodos de la historia reciente de España, permite conocer los términos del testimonio y el compromiso con los que el discurso literario ha contribuido al cambio social y a la defensa de una sociedad más justa e igualitaria, una visión que adquiere sin duda un carácter diferencial al ofrecerse desde la perspectiva de unas mujeres imbricadas en la esfera pública.

Recibido: $16 / 05 / 2018$

Aceptado: 19/09/2018 


\section{Referencias bibliográficas}

Caballé, Anna (2002), "La autobiografía escrita por mujeres: los vacíos en el estudio de un género", en Nieves Baranda Leturio y Lucía Monteo Gurruchaga, Las mujeres escritoras en la historia de la literatura española, Madrid: UNED, pp. 141-152.

Díaz Fernández, José (1930), El nuevo romanticismo. Polémica de arte, política $y$ literatura, Madrid: Zeus.

Ena Bordonada, Ángela (2011), "Jaque al ángel del hogar: Escritoras en busca de la nueva mujer del siglo XX", en Ma José Porro Herrera y Blas Sánchez Dueñas (coords.), La mujer y la transgresión de códigos en la literatura española, Córdoba: Universidad de Córdoba, pp. 89-111.

Garasa, Delfín Leocadio (1973), Literatura y Sociología, Buenos Aires: Troquel.

García-Pascual, Raquel (2012), "Protocolo de valoración del código de comunicación grotesco en las creadoras teatrales (siglos XX y XXI): teoría y práctica escénica", Signa, 21, pp. 13-53.

Hartwig, Susanne, ed. (2017), Ser y deber ser. Dilemas morales y conflictos éticos del siglo XX vistos a través de la ficción, Madrid-Frankfurt: Iberoamericana-Vervuert.

Johnson, Roberta y Maite Zubiaurre, eds. (2012), Antología del pensamiento feminista español (1726-2011), Madrid: Cátedra.

Montejo Gurruchaga, Lucía (2012), Discurso de autora. Género y censura en la narrativa española de posguerra. Madrid: UNED.

Nieva-de la Paz, Pilar (2018), Escritoras Españolas Contemporáneas. Identidad $y$ Vanguardia, Berlin: Peter Lang.

Sanz Villanueva, Santos (2010), La novela española durante el franquismo, Madrid: Gredos.

Tunón de Lara, Manuel (1974), Metodología de la historia social de España, México DF-Madrid: Siglo XXI.
Vilches-de Frutos, Francisca y Pilar Nieva-de la Paz (2012), "Representaciones de género en la Industria Cultural. Textos, imágenes, públicos y valor económico", en Francisca Vilches-de Frutos y Pilar Nieva-de la Paz (coords. y eds.), Imágenes femeninas en la literatura española y las artes escénicas, Philadelphia: Society of Spanish and Spanish-American Studies, pp. 15-34. 